DOI: $\underline{10.20472 / E S .2019 .8 .2 .003 ~}$

\title{
ENDOGENOUS FIRM LOCATION WITH A DECREASING DENSITY OF CONSUMERS
}

\section{JOHN HARTER}

\begin{abstract}
:
This note will use the Hotelling's line model with a non-uniform distribution of consumers. Instead, a linear, decreasing density is employed to represent a decreasing population density as distance from a metropolitan area is increased along some transportation artery. Entry is sequential, and the number of firms is assumed endogenous after an initial firm is located, making the entrants consider the possibility of later firms. Entrants into this market have neither maximum nor minimum differentiation. Earlier entrants generally locate closer to the population center with the possible exception of the equilibrium location closest to the densest point on the line. The differentiation increases as the firms are farther from the population center.
\end{abstract}

\section{Keywords:}

Location

Product differentiation

Hotelling model

JEL Classification: L19, R32, D21

\section{Authors:}

JOHN HARTER, Eastern Kentucky University, United States, Email: John.Harter@eku.edu

\section{Citation:}

JOHN HARTER (2019). Endogenous Firm Location with a Decreasing Density of Consumers. International Journal of Economic Sciences, Vol. VIII(2), pp. 35-44., 10.20472/ES.2019.8.2.003 


\section{Introduction}

Firms do not necessarily locate in metropolitan areas, but sometimes locate near them. As firms locate closer to the metropolitan area, the number of potential consumers increases, but so will the competition from other firms. Entrants, therefore, will want to balance the increase in the closeness of potential consumers with the expected increase in the closeness of other firms. This paper will use a modified Hotelling's line model (Hotelling, 1929) to examine entrants' behavior when the population density decreases as the firm locates farther from the population center, as might occur along a transportation artery.

There has been a great deal of work on the location/product differentiation framework proposed by Hotelling, and there have been many extensions (for a summary, see Biscala and Mota, 2013). For one relevant example, Prescott and Visscher (1977) introduced sequential entry. They found multiple equilibria, but these included equal spacing of three firms with the early entrants located outside the last entrant. Neven (1987) later allowed sequential entry, finding that early entrants will locate systematically around the center. However, that work assumed a uniform distribution of consumers and quadratic transportation costs.

Usually, the consumers in the Hotelling line model are assumed to be distributed uniformly. A few papers, however, have examined non-uniform consumer distributions. Shilony (1981) and Azar (2015) looked at duopolists' given locations, and examined the price competition. Others (Neven, 1986; Tabuchi and Thisse, 1995; Anderson, Goeree, and Ramer, 1997; and Meagher, Teo, and Wang, 2008) looked at locations, but examined duopolists and simultaneous entry. Calvó-Armengol and Zenou (2002) considered more than two firms, but an exogenously given number and still simultaneous entry. Their work also utilized a circular location model. Loertscher and Muehlheusser (2011) is one of the few to consider endogenous entry with non-uniform consumer distributions. The current paper uses a particular, asymmetric distribution, but allows an endogenous number of firms to enter sequentially. It is concerned with the location pattern and the sequence of entry of the firms.

\section{Model}

Consumers are distributed over a linear space, $[0, \alpha / \beta]$, with density given by the function $d=\alpha-\beta x$, where $x$ is the location of the consumer. Each consumer buys a quantity of one at the exogenously given price and will minimize transportation costs by purchasing from the closest firm. Formally, a utility-maximizing consumer at location $x$ who is buying from a firm at location, $x_{i}$, will have a utility of

$$
U\left(x, x_{i}\right)=\left\{\begin{array}{c}
s-\left(P+t\left|x-x_{i}\right|\right) Q \text { if } Q \geq 1 ; \text { and } \\
0 \text { otherwise }
\end{array}\right.
$$

where $s$ is the consumer's reservation price, $P$ is the mill price, and $t$ is the coefficient yielding a linear transportation cost. Following the literature, the reservation price, $s$, is assumed high enough that all consumers will buy. Since the delivered price (the mill price plus the transportation cost) is positive, the consumer will not choose a $Q$ greater than one. 
Profit-maximizing firms locate sequentially along the space. The number of firms is endogenous. Firm 0 is assumed to have entered at location $x_{0}=0$ before the game begins. For simplicity, assume all costs of production are zero, but there is a cost of entry, F. Without loss of generality, the firms are assumed to have a common price of $P=1$. After all firms have located, the consumers purchase from the firms. Because of the common price, the lowest delivered price a consumer faces is from the closest firm regardless of the value of $t$. This greatly eases computations since $Q=1$ for each consumer, $P=$ 1 , and does not affect the decisions of the firms or the consumers.

Define the subscripts for the locations, $\left\{x_{1}, x_{2}, \ldots, x_{N}\right\}$, such that $x_{1} \leq x_{2} \leq \ldots \leq$ $\mathrm{x}_{N}$. An interior firm located at $x_{i}$ would have profits given by

$$
\pi_{x_{i}}=\int_{\frac{x_{i-1}+x_{i}}{2}}^{\frac{x_{i}+x_{i+1}}{2}}(\alpha-\beta x) d x-F
$$

Since the density function is linear, this space is a trapezoid, and the profits can also be written as

$$
\pi_{x_{i}}=\left(\frac{x_{i+1}-x_{i-1}}{4}\right)\left(2 \propto-\frac{\beta}{2}\left(2 x_{i}+x_{i+1}+x_{i-1}\right)\right)-F .
$$

For ease of exposition, it might be easier to look separately at the revenue from the consumers to the firm's left and the revenue from the consumers to the firm's right. These revenues are denoted as the "left revenue" (LR) and the "right revenue" (RR). These revenues would be given by

$$
L R_{x_{i}}=\int_{\frac{x_{i-1}+x_{i}}{2}}^{x_{i}}(\alpha-\beta x) d x
$$

or (since it, too, is a trapezoid)

$$
L R_{x_{i}}=\left(\frac{x_{i}-x_{i-1}}{4}\right)\left(2 \propto-\frac{\beta}{2}\left(3 x_{i}+x_{i-1}\right)\right),
$$

for the left revenue, and

$$
R R_{x_{i}}=\int_{x_{i}}^{\frac{x_{i}+x_{i+1}}{2}}(\alpha-\beta x) d x
$$

or (since it, too, is a trapezoid)

$$
R R_{x_{i}}=\left(\frac{x_{i+1}-x_{i}}{4}\right)\left(2 \propto-\frac{\beta}{2}\left(3 x_{i}+x_{i+1}\right)\right)
$$

for the right revenue (as in Figure 1). 


\section{Figure 1: Left Revenue and Right Revenue for Firm i}

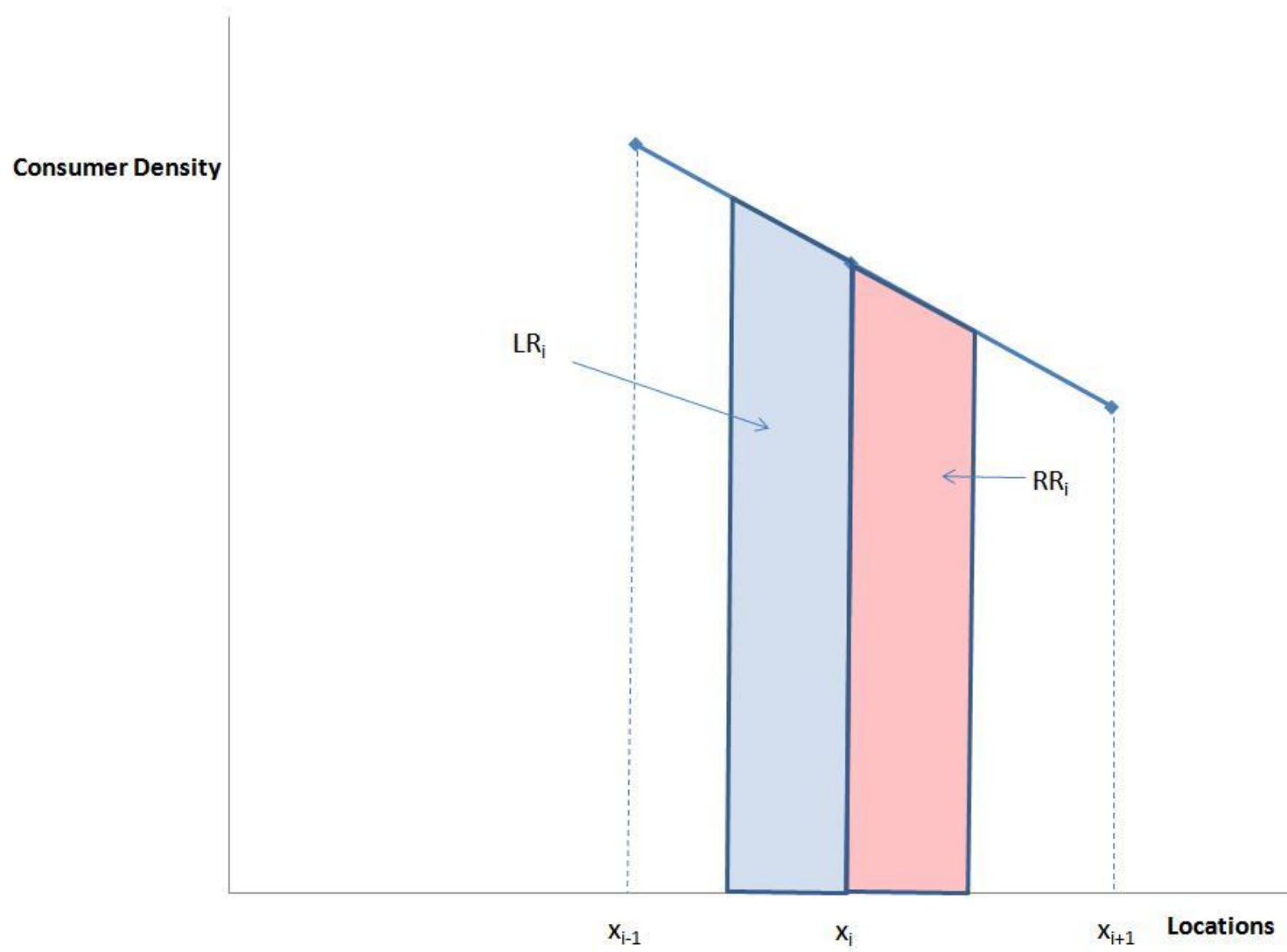

\section{Results}

The equilibrium set of locations is such that the right revenue of each firm is exactly equal to the cost of entry, F. In other words, each firm is located so that it would not be profitable for an $N+1^{\text {th }}$ firm to locate to its right.

Proposition 1: The equilibrium is $\left\{x_{1}, x_{2}, \ldots, x_{N}\right\}$ such that:

$$
\begin{aligned}
& R R_{x_{N}}=\left(\frac{1}{2}\right)\left(\frac{\alpha}{\beta}-x_{N}\right)\left(x_{N}-\beta x_{N}\right)=F ; \\
& R R_{x_{N-1}}=\left(\frac{x_{N}-x_{N-1}}{4}\right)\left(2 \propto-\frac{\beta}{2}\left(3 x_{N-1}+x_{N}\right)\right)=F ;
\end{aligned}
$$

and so on until

(10) $R R_{x_{1}}=\left(\frac{x_{2}-x_{1}}{4}\right)\left(2 \propto-\frac{\beta}{2}\left(3 x_{1}+x_{2}\right)\right)=F$; and

(11) $R R_{x_{0}}=\left(\frac{x_{1}-x_{0}}{4}\right)\left(2 \propto-\frac{\beta}{2}\left(3 x_{0}+x_{1}\right)\right) \leq F$.

Proof:

The equilibrium must contain firms located at these points. 
If $R R_{X N}>F$, then there exists a location $x_{N+1}=x_{N}+\varepsilon$ such that $R R_{X N+1}=F$ and $L R_{X N+1}>0$. Therefore, it is not an equilibrium for the firm farthest to the right to locate at that location, $x_{N}$.

If $R R_{X N}<F$, then there are two possibilities for the firm's total revenues $\left(T R_{X N}\right): T R_{X N}<F$ or $T R_{X N} \geq F$. First, if $T R_{X N}<F$, then it is not an equilibrium for the firm to have entered at all. If $T R_{X N} \geq F$ (and $R R_{X N}<F$ ), then $L R_{X N}>0$. If the firm instead chooses location $x_{N^{\prime}}=x_{N}-\varepsilon$ so that $R R_{X_{N}}<F$ and $x_{N}>x_{N-1}$, then $T R_{X_{N}}>T R_{X N}$. The firm could gain consumers by moving to the left. Thus, it cannot be an equilibrium for $R R_{X N}<F$.

Therefore, $R R_{X N}=F$, and equation (8) holds.

Similarly, if $R R_{X N-1}>F$, then a location, $x_{N^{\prime}}$, exists so that a firm could locate where $x_{N-1}<x_{N^{\prime}}<x_{N}$, and $R R_{X_{N}}=F$ and $L R_{X^{\prime}}>0$. Thus, it is not an equilibrium for the firm second from the right to locate so that $R R_{X N-1}>F$.

If, on the other hand, $R R_{X N-1}<F$, then either $T R_{X N-1}<F$ or $T R_{X N-1} \geq F$. However, $T R_{X N-1}<F$ cannot be an equilibrium location since not entering would be preferred. If $T R_{X N-1} \geq F$ and $R R_{X N-1}<F$, Then $L R_{X N-1}>0$. If the firm locates at $x_{N-1}{ }^{\prime}=X_{N-1}-\varepsilon$, where $R R_{X N-1} \leq F$, but $T R_{X N-1},>T R_{X N-1}$. Since the density of the consumers is linear and decreasing as we move away from location zero, a movement to the left will not change the width of the firm's market share. It will change the height, however - increasing the total revenue with a movement to the left.

Therefore, $R R_{X N-1}=F$, and equation (9) holds.

Similarly, for all firms, the right revenue must equal $\mathrm{F}$. Also, however, no $\mathrm{N}+1^{\text {th }}$ firm could profitably enter. Therefore, equation (11) must also hold.

These locations constitute the Nash Equilibrium, regardless of which firm locates at which location. There is neither maximum nor minimum differentiation. When the parameters are such that only one firm enters, it does not locate at zero (where the incumbent is located), nor at the opposite endpoint. With more entrants, the firms are relatively evenly spaced, except that the distance between firms does increase as the firms locate farther from the left endpoint.

As noted by Loerscher and Muehlheusser (2011), the equilibrium locations are independent of the sequence of location selection. Consequently, as firms enter, they will choose the most profitable of the equilibrium locations that is not yet taken. For the subgame-perfect equilibrium, the firms will generally select the equilibrium location farthest to the left, with the possible exception of the location nearest to Firm 0.

Define the equilibrium locations $\left\{x^{1}, x^{2}, \ldots, x^{N}\right\}$, such that $\pi\left(x^{1}\right) \geq \pi\left(x^{2}\right) \geq \ldots \geq \pi($ $\left.x^{N}\right)$. Notice that $\left\{x^{1}, x^{2}, \ldots, x^{N}\right\}$ is not necessarily the same as $\left\{x_{1}, x_{2}, \ldots, x_{N}\right\}$. It is easy to show that for any two firm locations except for the one nearest to 
Firm 0, the firm on the left will have higher profits. The firm location nearest to Firm 0 might yield profits approaching zero (if it is located very near location zero, implying the left revenue is close to zero), but it might also yield higher profits than any other location, depending on the parameters, $\alpha, \beta$, and $F$.

The first firm will choose to locate at the location farthest to the left or the second to the left. The next firm will then locate either farthest to the left (if it is still available) or at the next equilibrium location to the right of the first firm. Each succeeding firm locates at either the location farthest to the left (if it is still available) or the next equilibrium location to the right of the firms before it.

Therefore, there isn't the minimum differentiation of Hotelling (1929) or Xefteris (2013), nor the maximum differentiation of d'Aspremont et al. (1979), and especially not the more-than-maximum differentiation of Harter (1996). The spacing of the firms is not equal (as assumed by Calvó-Armengol and Zenou, 2002). Also, unlike Neven (1987), the earlier firms tend to locate to the left instead of near the center of the space. This is intuitive since the density of consumers is greatest on the left instead of constant.

These results mirror those of Loertscher and Muehlheusser (2011), where they point out that lower costs of entry induce more firms to enter, that firms locate closer together when consumer preferences are more dense, and that profits tend to be higher in those areas where consumer preferences are more dense. All three of those results hold here.

Proposition 2: The unique subgame-perfect equilibrium is for the firms to choose the equilibrium locations such that Firm $i$ selects $x^{i}$, for all $i$.

There is, therefore, a first-mover advantage as each firm selects the location which yields the highest level of profits of those remaining.

\section{Example}

As an example, and to demonstrate the equilibrium, let $\alpha=100, \beta=2$, and $F=$ 225. For these parameters, the equilibrium locations are given in Table 1 below (rounded to two decimal places).

Table 1: Locations and Profits when $\alpha=100 \beta=2$, and F = 225

\begin{tabular}{|c|c|c|c|}
\hline & Locations & Profits & Sequence \\
\hline $\mathrm{x}_{1}$ & 1.48 & 72.48 & $\mathrm{x}^{6}$ \\
\hline $\mathrm{x}_{2}$ & 6.24 & 213.70 & $\mathrm{x}^{1}$ \\
\hline $\mathrm{x}_{3}$ & 11.54 & 210.95 & $\mathrm{x}^{2}$ \\
\hline $\mathrm{x}_{4}$ & 17.63 & 206.45 & $\mathrm{x}^{3}$ \\
\hline $\mathrm{x}_{5}$ & 25.00 & 197.84 & $\mathrm{x}^{4}$ \\
\hline $\mathrm{x}_{6}$ & 35.00 & 175.00 & $\mathrm{x}^{5}$ \\
\hline
\end{tabular}

Notice that the distance between locations increases to the right. Each firm is locating so that its right revenue is exactly equal to the cost of entry, $F$. 
Because the density of consumers is lower for firms located to the right, they can block off a larger width. Consequently, the sixth location attracts all consumers from the location 35 to the location 50 for its right revenue. The first location, however, is only able to deter entry from its location (1.48) to the midpoint between it and the next firm (3.86) for its right revenue.

Notice also that the profits are generally decreasing to the right, except for $x_{1}$. Since each firm is located so that its right revenue is equal to the cost of entering, $F$, its profits is simply its left revenue. The location to the left, $x_{1}$, might be far enough from 0 that its profits are higher than any other location. Alternatively, the profits arising from the location, $x_{1}$, might be very close to zero. In other words, for $\alpha>0, \beta>0$, and $F>0,0<\pi\left(x_{1}\right)<F$.

In the subgame perfect equilibrium for these parameters, the first entrant will choose the location $x^{1}=6.24\left(=x_{2}\right)$, the second entrant will choose $x^{2}=11.54$ $\left(=x_{3}\right)$, and so on. The sixth entrant will select location $x^{6}=1.48\left(=x_{1}\right)$.

If, however, we change only the cost of entry so that $\alpha=100, \beta=2$, and $F=$ 202 , then the location closest to $x=0$ is not the least profitable.

Table 2: Locations and Profits when $\alpha=100 \beta=2$, and $F=202$

\begin{tabular}{|c|c|c|c|}
\hline & Locations & Profits & Sequence \\
\hline $\mathrm{x}_{1}$ & 4.03 & 189.29 & $\mathrm{x}^{3}$ \\
\hline $\mathrm{x}_{2}$ & 8.53 & 191.86 & $\mathrm{x}^{1}$ \\
\hline $\mathrm{x}_{3}$ & 13.56 & 189.38 & $\mathrm{x}^{2}$ \\
\hline $\mathrm{x}_{4}$ & 19.33 & 185.35 & $\mathrm{x}^{4}$ \\
\hline $\mathrm{x}_{5}$ & 26.31 & 177.62 & $\mathrm{x}^{5}$ \\
\hline $\mathrm{x}_{6}$ & 35.79 & 157.11 & $\mathrm{x}^{6}$ \\
\hline
\end{tabular}

With these costs to entry $(F=202)$, the location farthest to the right must be slightly to the right of where it would be when $F=225$. This occurs in order to prevent further entry to the right of location, $x_{6}$. Each of the locations is slightly to the right with the lower entry cost. This increases the distance between $x_{0}$ and $x_{1}$. While it is not sufficient to allow a seventh entrant (as would occur if $F=200$ ), this does increase the profits of the firm locating at $x_{1}$. Consequently, $x_{1}$ is no longer the least-profitable equilibrium location, and would be selected by the third entrant.

\section{Social Welfare}

Social welfare is problematic in this model. For a given number of firms, a social planner would wish to minimize the deadweight loss due to transportation. So, for example, for two firms, the deadweight loss would be

$$
\begin{aligned}
& D W L=\int_{0}^{x_{1} / 2}(\alpha-\beta x)(x-0) d x+\int_{x_{1} / 2}^{x_{1}}(\alpha-\beta x)\left(x_{1}-x\right) d x+\int_{x_{1}}^{\left(x_{1}+x_{2}\right) / 2}(\alpha-\beta x)(x- \\
& \left.x_{1}\right) d x+\int_{\left(x_{1}-x_{2}\right) / 2}^{x_{2}}(\alpha-\beta x)\left(x_{2}-x\right) d x+\int_{x_{2}}^{\alpha / \beta}(\alpha-\beta x)\left(x-x_{2}\right) d x .
\end{aligned}
$$


The social planner would also have to take into account the cost of entry, F. If the decrease in deadweight loss from having a third firm would exceed the additional cost of entry, then the social planner would want a third firm. Unfortunately, the firms do not consider the transportation costs, but do consider the cost of entry.

As an example, using some of the variables from the example above, when $\alpha=$ $100, \beta=2$, and there is only one firm, the socially optimal location would be at $x_{1}=25$. However, the single firm would only locate there if the right revenue is equal to the cost of entry, which in this case would be $F=625$. In that case, the cost of entry, $F$, is not high enough to deter a second firm from entering. The only way to have a single firm entering, we would need a higher cost of entry, but then the firm would move to the left of the socially-optimal location.

With the uniform distribution of consumers, the cost of entry, F, can be chosen to maximize total welfare. However, that it not possible with non-uniform distributions, such as in this paper (Loertscher and Muehlheusser, 2011).

\section{Conclusions}

Most work on locations in the Hotelling's line literature assumes a uniform distribution of consumers. This seems unrealistic for some situations, however, as population generally decreases as transportation arteries leave a metropolitan area. Those works that do not have a uniform distribution usually examine a fixed number of entrants and simultaneous entry. This note looks at the equilibrium when the population density is decreasing at a constant rate away from the population center and the firms enter sequentially. Entrants into this market have neither maximum nor minimum differentiation. The differentiation increases as the firms are farther from the population center. Earlier entrants tend to locate closer to the population center as long as they do not locate too close to the existing firm in the city.

A natural extension to the note is to add price competition, if possible. Discount shopping malls have long located outside of the main population centers. It would be interesting to see if this might result from price competition. Mostly, closer firms actually have higher profits than the firms that are more spread out because the density of consumers is much higher. Endogenizing price could well change that as the closer firms would be more competitive over price.

Many authors have extended the Hotelling's line model by using a locationprice game where the firms locate, then compete in prices. This can change the location from Hotelling's minimum-differentiation result in duopoly because firms producing identical products would essentially be engaging in Bertrand competition with its resulting low profits (d'Aspremont et al, 1979). However, d'Aspremont et al. needed to change the transportation costs for an equilibrium in the location-price game to exist. Xefteris (2013) did retain the minimumdifferentiation result, but by assuming, in part, an infinite reservation price on the part of the consumers. Montes-Rojas (2015) looked at, essentially, an endogenous number of entrants, but assumed an infinite width to the distribution of consumers. Others have noted the difficulty with ensuring an 
equilibrium exists as the number of firms increases beyond two (e.g., Economides, 1993, or Brenner, 2005). Loertscher and Muehlheusser (2011) and Hong (1990) give many examples, however, where the firms would not compete using price. For instance, media markets often have low or even zero prices, but the firms earn profits from advertising, which is based on market share. Alternatively, there could be governmental price controls. Thus, it is useful to examine the location strategies without price competition separately from any effect the price competition would exert on those location strategies.

Alternatively, locating outside the population center might result from a nonconstant cost of location, as introduced by Hinloopen and Martin (2017). Their work, however, only looked at duopoly and used a distribution of costs which does not fit this model.

\section{References}

Anderson, S.P., Goeree, J.K., and Ramer, R. (1997) Location, Location, Location. Journal of Economic Theory. $77 . \quad 102-127$. https://doi.org/10.1006/jeth.1997.2323

Azar, O.H. (2015) A Linear City Model with Asymmetric Consumer Distribution. PLos One. 10(6): e0129068. https://doi.org/10.1371/journal.pone.0129068

Biscala, R., and Mota, I. (2013) Models of Spatial Competition: A Critical Review. Papers in Regional Science. 92(4). 851-871. https://doi.org/10.1111/j.1435-5957.2012.00441.x

Brenner, S. (2005) Hotelling Games with Three, Four, and More Players. Journal of Regional Science. 45(4). 851-864. https://doi.org/10.1111/j.00224146.2005.00395.x

Calvó-Armengol, A., and Zenou, Y. (2002) The Importance of the Distribution of Consumers in Horizontal Product Differentiation. Journal of Regional Science. 42. 793-803. https://doi.org/10.1111/1467-9787.00282

D'Aspremont, C., Gabszewicz, J.J., and Thisse, J.-F. (1979) On Hotelling's "Stability in Competition." Econometrica. 47. 1145-1150. https://doi.org/10.2307/1911955

Economides, N. (1993) Hotelling's "Main Street" with More than Two Competitors. Journal of Regional Science. 33(3). 303-319. https://doi.org/10.1111/j.1467-9787.1993.tb00228.x

Harter, J.F.R. (1996) When Technology and Preferences Differ in Hotelling's Competition. Journal of Economics (MVEA). 22(2). 97-100.

Hinloopen, J., and Martin, S. (2017) Costly Location in Hotelling Duopoly. Research in Economics. 71. 118-128. https://doi.org/10.1016/j.rie.2016.08.002

Hong, G-S. (1990) Location Equilibria in Spatial Competition under Price Control. The Korean Journal of Regional Science. 6(2). 149-153. 
Hotelling, H. (1929) Stability in Competition. Economic Journal. 39. 41-57. https://doi.org/10.2307/2224214

Loertscher, S., and Muehlheusser, G. (2011) Sequential Location Games. RAND Journal of Economics. 42(4). 639-663. https://doi.org/10.1111/j.1756$2171.2011 .00148 . x$

Meagher, K., Teo, E., and Wang, W. (2008) A Duopoly Location Toolkit: Consumer Densities Which Yield Unique Spatial Duopoly Equilibria. The B.E. Journal of Theoretical Economics. 8. Article 14. https://doi.org/10.2202/19351704.1445

Montes-Rojas, G. (2015) Spatial Competition and the Location of Firms with Non-Uniformly Distributed Consumers. Revista de Economía Política de Buenos Aires. 14.83-107.

Neven, D. (1986) On Hotelling's Competition with Non-Uniform Customer Distributions. Economics Letters. 21. 121-126. https://doi.org/10.1016/01651765(86)90049-2

Neven, D. (1987) Endogenous Sequential Entry in a Spatial Model. International Journal of Industrial Organization. 5. 419-434. https://doi.org/10.1016/S0167-7187(87)80004-8

Prescott, E.C, and Visscher, M. (1977) Sequential Location among Firms with Foresight. The Bell Journal of Economics. 8(2). 378-393. https://doi.org/10.2307/3003293

Shilony, Y. (1981) Hotelling's Competition with General Customer Distributions. Economics Letters. 8. 39-45. https://doi.org/10.1016/01651765(81)90090-2

Tabuchi, T., and Thisse, J.-F. (1995) Asymmetric Equilibria in Spatial Competition. International Journal of Industrial Organization. 13. 213-227. https://doi.org/10.1016/0167-7187(94)00449-C

Xefteris, D. (2013) Hotelling Was Right. Journal of Economics \& Management Strategy. 22(4). 706-712. https://doi.org/10.1111/jems.12032 